\title{
A NEW PARASITIC CREMATOGASTER FROM INDIANA
}

\section{By William MORTON WHEELER ${ }^{1}$}

For many years I have suspected that some of the species of the huge, cosmopolitan ant-genus Crematogaster might prove to be social parasites. My grounds for this suspicion were the fact that one common Neotropical form, $C$. (Orthocrema) limata F. Smith subsp. parabiotica Forel commonly lives in parabiosis with Camponotus (Myrmothrix) femoratus Fabr. and Dolichoderus (Monacis) parabioticus Forel, and the fact that the females of certain subgenera, notably those of Crematogaster sens. str. (as shown in the type of the genus, C. acuta Fabr.), Nematocrema and Atopogyne, have small subtriangular gasters like those of the workers and unlike the voluminous, suboblong gasters of the females in other subgenera. This small size and worker-like aspect of the female gaster is, of course, a sign of underdevelopment of the ovaries and an indication that the female may be parasitic, or in other words, adapted to invading and securing adoption in a flourishing colony of some allied species in order to provide for the maturation of her ovarian eggs and the rearing of her offspring.

That a parasitic Crematogaster has probably been found at last, not in the tropics but in our own country, is suggested by a study of some specimens sent me for identification by Professor C. H. Kennedy. They comprise 43 workers and 7 black winged females which undoubtedly belong to a form of our common acrobat ant, Crematogaster (Acrocoelia) lineolata Say (near var. cerasi Fitch, but darker), together with 14 females and six males of a distinctly different species. The females of the latter are very small and have the head, thorax and pedicel red as in the

\footnotetext{
${ }^{1}$ Contribution from the Entomological Laboratory of the Bussey Institution, Harvard University, No. 335.
} 
subsp. laevinuscula Mayr (with the vars. clara Mayr and californica Emery) common in the Gulf States and California. The six males seem to be cospecific with the small females, since their wings are of the same color and also like those of laeviuscula. All the forms cited above were taken Sept. 22, 1929 in Robinson Park, Fort Wayne, Indiana, by Professor Kennedy from the same nest, which, he says (in litt.) "was large and under the loose bark of a cottonwood log. It contained workers, males, large brownish-black queens and many smaller shining red and black queens. These latter queens were a shining cherry red and a pitch black in life and acted differently from the ordinary queens. My memory is that they were more active. They were so different that I cannot believe they are the same species."

The specimens and Professor Kennedy's notes suggest the following reflections:

1. The colony might be said to represent a distinct and hitherto unknown variety of $C$. lineolata, characterized by having dimorphic, or $\mathrm{A}$ - and $\mathrm{B}$ - females, like Lasius (Acanthomyops) latipes Walsh of North America and L. (Dendrolasius) spathepus of Japan. This is very improbable, if, as I believe, the males belong to the small red and black females.

2. It is much more probable that these females and the males represent a distinct species parasitic in a flourishing $C$. lineolata colony, but this again suggests the question as to whether the parasite possesses a worker caste or is workerless like such ants as Anergates, Anergatides, Epoecus and Wheeleriella.

3. The absence of any workers other than those of the common lineolata in the material examined strongly indicates that the parasitic species is represented only by females and males, as in the genera just mentioned.

4. If this interpretation is adopted we must suppose that the parasitic Crematogaster is phylogenetically a comparatively recent off-shoot of the host species, lineolata, because its morphological modifications are so feeble. In this respect it resembles such perma- 
nent social parasites as Vespa austriaca and arctica among wasps, the species of the genus Psithyrus among bumble bees and those of the genera Wheeleriella and Epoecus among ants, rather than Anergates and Anergatides, in which the modifications due to parasitism are so considerable.

5. There is only one consideration that would seem to cast doubt on the interpretion of the small red and black females and their males as workerless parasites and that is the presence of perfectly developed virgin lineolata females in the same nest, because we should expect the mother queen of the host colony to have been eliminated just after the intrusion of the parasite and hence to have been incapable of leaving either female or worker offspring. It is conceivable, however, either that the mother queen of the new Crematogaster may manage to secure her own adoption and the rearing of her offspring in the lineolata colony without supplanting its mother queen, or that the suppression of the latter may be greatly delayed and the rearing to maturity of her female offspring be permitted by the worker personnel.

6. That the small red and black females are parasites and are fertilized in the nest (as in Anergates atratulus, though this form has wingless, pupa-like males, so that a marriage flight is out of the question) is indicated by the fact that the 14 specimens are in part winged and in part wholly or partially deälated, whereas the seven females of lineolata show no indications of losing their wings. And though Miss A. M. Fielde found that mating may take place in the nest in our common lineolata, the conditions in Professor Kennedy's colony suggest that the red and black females are more precocious than the winged females of their host. The differences in the behavior of the two kinds of females, noticed by Professor Kennedy, are also very suggestive in this connection.

As shown in the following description, the female of the new Crematogaster may be readily distinguished from the 
female of lineolata or of any of its various subspecies and varieties, but the male has departed so little from that of its host, that its characters are rather elusive. This is not surprising since the male is the conservative sex among the Formicidæ.

\section{Crematogaster (Acrocoelia) kennedyi sp. nov.}

Female.-Length $5-6 \mathrm{~mm}$.; forewing $5 \mathrm{~mm}$.

Decidedly smaller than the females of lineolata, its subspecies laeviuscula Mayr, coarctata Mayr, etc., which measure 8-9 mm., with the anterior wings 7-7.5 mm. Head less narrowed anteriorly and more rectangular, owing to the sides being straight and the posterior corners less rounded. Antennæ longer, the scapes extending a distance equal to their greatest diameter beyond the posterior corners (not reaching the posterior corners in lineolata). Thorax shorter and stouter, the mesonotum being nearly as broad as long (decidedly longer than broad in lineolata), the epinotal spines more acute and acuminate, and the base of the epinotum external to the spines conspicuously swollen. Dorsal surface of petiole more convex, with straight instead of concave anterior border, its sides less converging posteriorly; postpetiole more broadly grooved or impressed in the middle behind. Gaster much shorter in proportion to its width, less parallel-sided, more subtriangular and therefore more like that of the worker lineolata. Legs rather short.

Even smoother and more shining than the subsp. laeviuscula. Mandibles coarsely striato-punctate. Head very finely striated anteriorly, rather sparsely and finely punctate behind; thorax and gaster with similar but even sparser punctures; mesopleuræ and sides of epinotum less shining than the mesonotum, scutellum, postpetiole and gaster, longitudinally rugulose; petiole subopaque, very finely granular. Antennal scapes and legs distinctly punctate.

Hairs glistening, yellowish, erect or suberect, much more abundant, much shorter and of much more even length on the head, thorax and gaster than in lineolata, and conspicuously long and abundant on the petiole and postpetiole. 
Hairs on the scapes and legs slightly longer and less appressed than in lineolata.

Head, thorax, pedicel, coxæ and femora and more or less of the venter of the first gastric segment bright yellowish red, more vivid than in the female of the var. clara Mayr of the subsp. laeviuscula. Gaster scutellum, metanotum and three large elongate spots on the metanotum, one anteromedian, the others parapsidal, jet black; mandibles, antennæ, tibiæ, knees and tarsi darker and more brownish red; bases and sometimes the whole of the scapes, the tips of the funicular clubs, the ventral portions of the mesosterna, the inner border of each ocellus and the posterior corners of the head, more or less blackened or infuscated. Wings whitish hyaline, the pterostigma and anterior veins of the forewings very faintly yellowish, the remaining veins colorless.

\section{Male.-Length $4 \mathrm{~mm}$.}

Very similar to the male of lineolata but somewhat more slender; gaster, especially, much narrower and more elongate. Mandibles more linear and narrower, furnished with three more distinctly equal denticles. Funicular joints apparently a little more cylindrical and less monillate. Pronotum distinctly less convex anteriorly and less overarching the pronotum. Epinotum more rounded with less distinct base and declivity and no indications of teeth, except in one of the six specimens.

Somewhat smoother and more shining than the male of lineolata and more like that of laeviuscula. Mesonotum very finely and rather indistinctly striated and sparsely punctate.

Hairs whitish, almost lacking on the head, thorax and gaster, where they are present, though sparse, in lineolata; gaster and legs merely with short, sparse, appressed pubescence; antennæ and genital appendages with short, erect or suberect, very dense white pubescence.

Jet black; mandibles, gaster, antennæ, legs and alar insertions dark brown. Wings whitish hyaline with the pterostigma and anterior veins of forewings even more feebly 
tinged with yellowish than in the female; remaining veins colorless.

In conclusion I would suggest that those who encounter flourishing colonies of our common $C$. lineolata, especially during the late summer, scrutinize their various castes with great care and, in the event of again finding the small red and black females of $C$. kennedyi, keep them in artificial nests and observe their adoptive behavior in uninfested colonies of lineolata with and without their mother queens. 

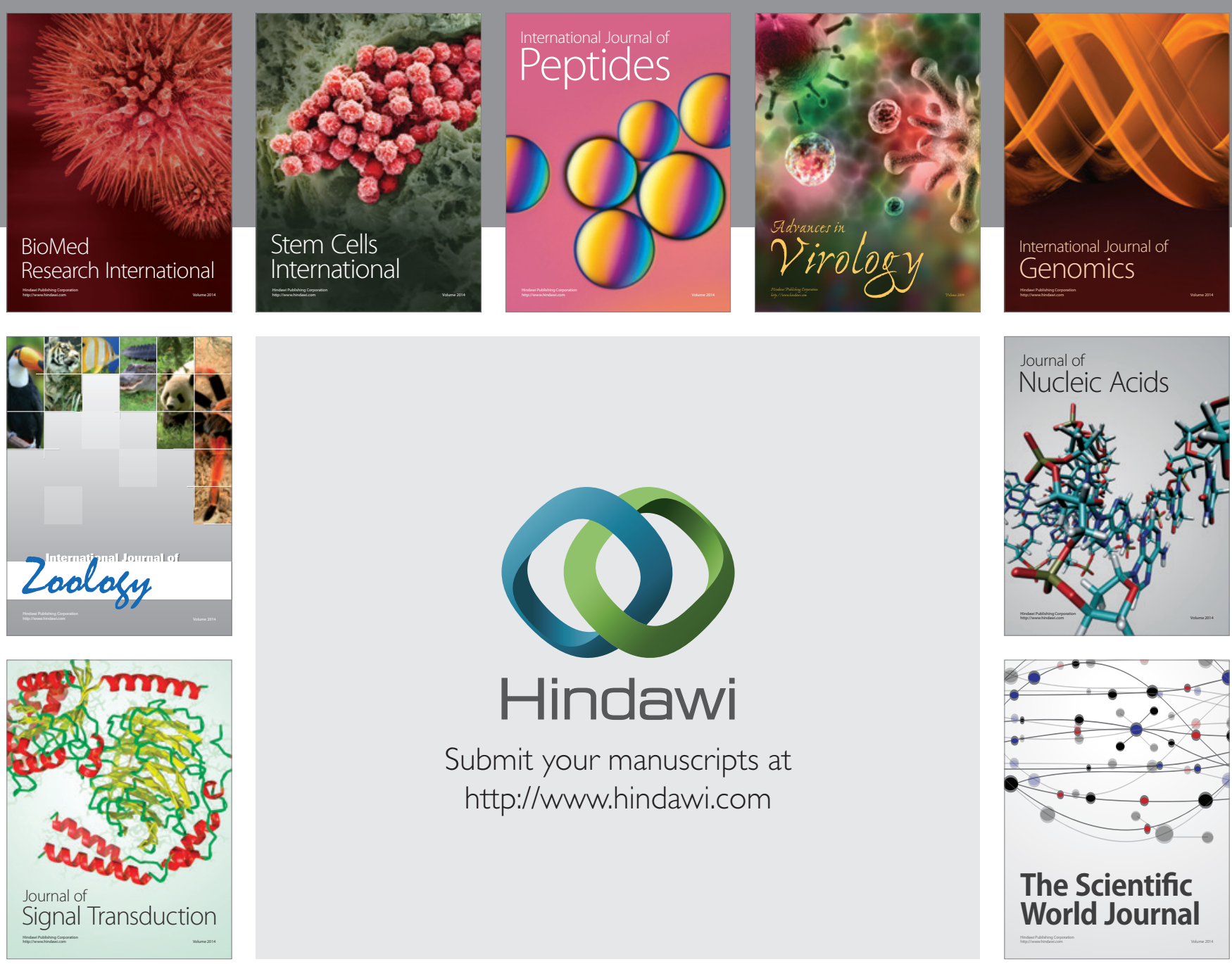

Submit your manuscripts at

http://www.hindawi.com
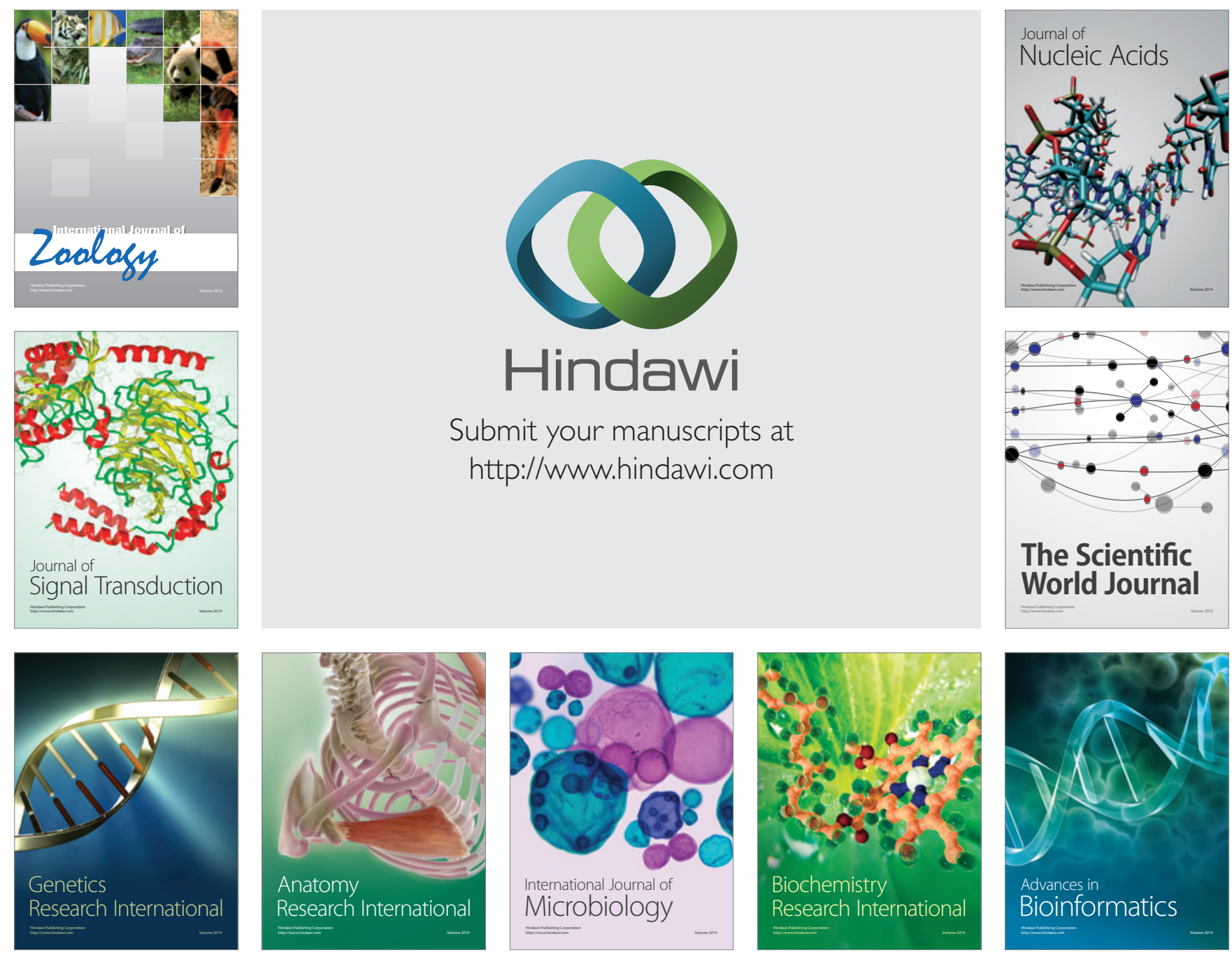

The Scientific World Journal
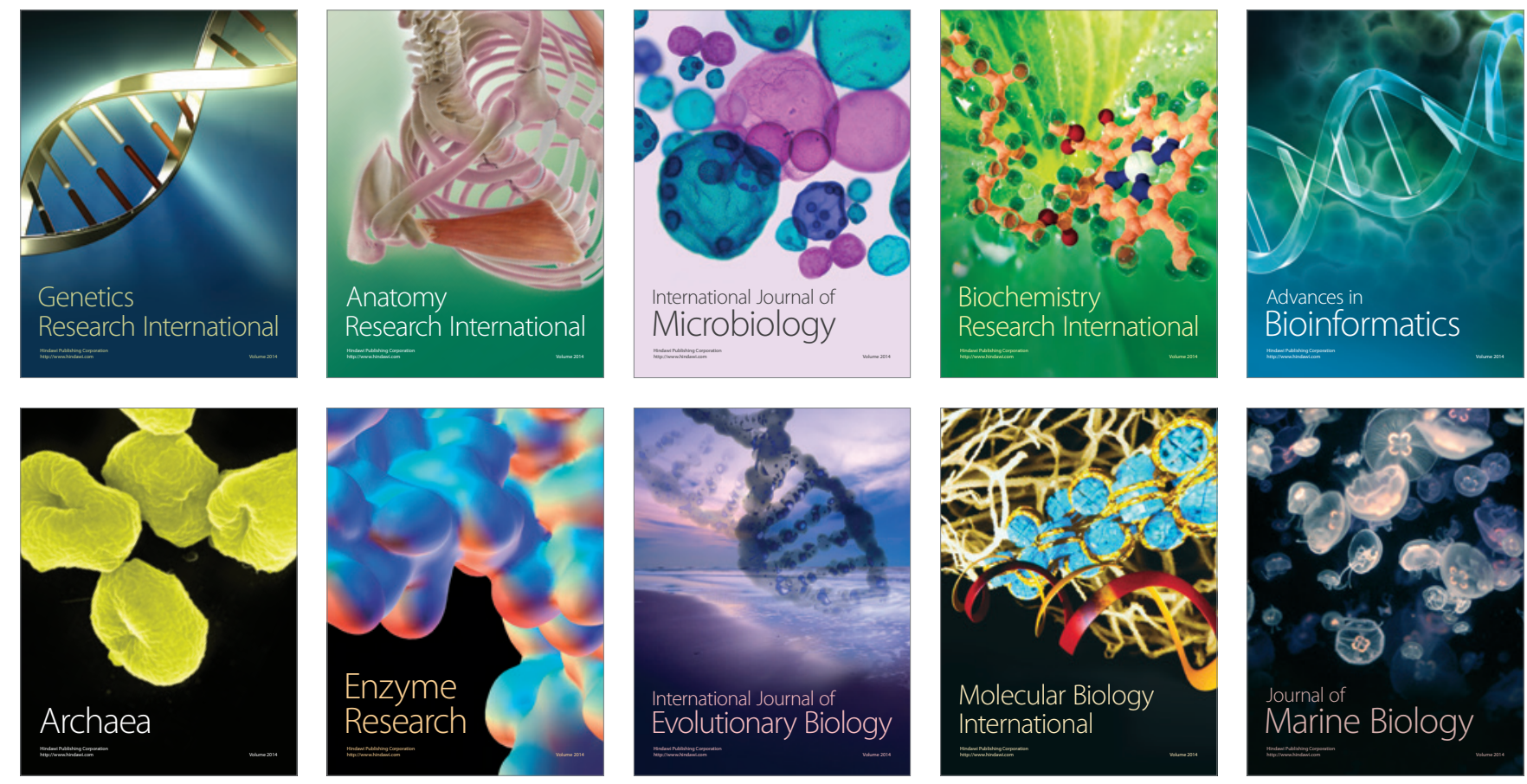